Herrera, R.F., Mourgues, C., and Alarcón, L.F. (2018). “Assessment of Lean practices, performance and social networks in Chilean airport projects." In: Proc. $26^{\text {th }}$ Annual Conference of the International. Group for Lean Construction (IGLC), González, V.A. (ed.), Chennai, India, pp. 603-613. DOI: doi.org/10.24928/2018/0493. Available at: www.iglc.net.

\title{
ASSESSMENT OF LEAN PRACTICES, PERFORMANCE AND SOCIAL NETWORKS IN CHILEAN AIRPORT PROJECTS
}

\author{
Rodrigo F. Herrera1 ${ }^{1}$, Claudio Mourgues ${ }^{2}$ and Luis F. Alarcón ${ }^{3}$
}

\begin{abstract}
Airport projects are complex in nature because they include several specialists from the public and private sector who must temporarily interact for the fulfillment of previously defined objectives. The design of these types of public projects in Chile does not apply the Lean philosophy in a formal way or Lean management tools; therefore, it is necessary to assess the management practices, performance and organizational logic that are currently generated in these types of projects. This is fundamental to understanding how professionals who are involved in the development of airport project design interact with each other. The objective of this paper is to understand the functioning and performance of the temporary organizations that are generated in the development of airport project design. To achieve this goal, it is necessary to assess Lean management practices, performance and interaction among the professionals of this temporary organization. This was carried out in 9 Chilean airport projects that showed an exhaustive management of requirements; however, this does not include all of the stakeholders, which generates low levels of interaction in the organization, directly affecting the performance of the project due to high levels of rework.
\end{abstract}

\section{KEYWORDS}

Lean practices, performance, social networks analysis, airport project.

\section{INTRODUCTION}

The industry of architecture, engineering and construction (AEC) is fragmented into several specialties, which appear at different stages during a product's life cycle (Love et al. 2002). Although fragmentation generates a high level of specialization in each of the

1 PhD candidate, Department of Construction Engineering and Management, Pontificia Universidad Católica de Chile, Professor, School of Civil Engineering, Pontificia Universidad Católica de Valparaíso, Chile, +5694413 2109, rodrigo.herrera@pucv.cl

2 Assistant Professor, Ph.D., Department of Construction Engineering and Management, Pontificia Universidad Católica de Chile, Santiago, Chile, cmourgue @ing.puc.cl

3 Professor, Ph.D., Department of Construction Engineering and Management, Pontificia Universidad Católica de Chile, Santiago, Chile, lalarcon@ing.puc.cl 
disciplines, its integration becomes more complex as the number of actors involved leads to increases in work breakdowns (Thomas \& Tang 2010).

Poor integration in work teams of the AEC industry can generate deficient performance, both in the realization of each of its stages (design, construction, maintenance, operation and deconstruction) and globally in the product's life cycle (Baiden et al. 2006). Low performance is generated due to the realization of activities that do not add value and that are considered as project wastes, such as rework and waiting times, among others (Aziz \& Hafez 2013). In particular, the design stage is fundamental in the life cycle of a project because the decisions taken in this instance can significantly affect the following stages. In addition, the costs of changes in the design stage are negligible compared to the costs of changes in future stages (AIA 2007), which represents a great potential to make improvements to the project.

Airport projects are complex in nature because they include several specialists from the public and private sector who must interact temporarily for the fulfillment of previously defined objectives. These objectives come from the transportation demands coming from the community, the requirements and needs of the airport organizations and the standards and regulations required for the airport's proper functioning. In addition, most airport projects require that the airport, or aerodrome, continue to operate normally during the construction phase of the new project.

For these reasons, it is fundamental to assess the relation among lean management practices, performance and organizational logics (interaction patterns) in the design team of these types of projects. Thus, the objective of this paper is to understand the functioning and performance of the temporary organizations that design airport projects, making a comparison between projects in preliminary and final design.

\section{BACKGROUND}

\section{LEAN PRACTICES IN DESIGN}

The literature shows several applications of Lean practices in design. Fosse \& Ballard (2016) presented a case study that shows the change between traditional planning and planning using Last Planner System (LPS) at the design stage. Although they did not present evidence of changes in project performance, they concluded that the degree of satisfaction of the project's stakeholders increases when LPS is used. Knotten et al. (2016) emphasized that the use of LPS and collaborative planning in the design reinforces trust and commitment among the members of the team, both being considered as fundamental elements for having an effective team (Svalestuen et al. 2015).

Lean Design introduces several elements with the aim of reducing rework and unnecessary tasks (Gambatese et al. 2017), for example, the early involvement of the client, maximization of value, identification of the needs and objectives of all interested parties, simultaneous design of the product and the process, and delaying the decisionmaking until the last responsible moment. These Lean Design elements are embedded in several Lean tools and methods such as Target Value Design, Set-Based Design, Building Information Models, Choosing by Advantages, and LPS. 


\section{KEY PERFORMANCE INDICATORS}

There are several performance indicators associated with the results of the construction process (Chan \& Chan 2004); however, when the indicators of the design process are revised, the checklist is smaller. Some metrics used to measure design productivity include hours per drawing and hours per number of elements designed (Ebrahimy \& Rokni 2010); other metrics are associated with the quality of the design and are calculated from the number of occurrence of design errors (Al Hattab \& Hamzeh 2015). Freire \& Alarcón (2002) included, as an indicator of productivity, the percentage of activities that do not add value. Later, Coates et al. (2010) presented a set of indicators to measure the efficiency of the design process, such as hours spent per project, cost efficiency, development speed, income per capita, and cash flow.

\section{INTERACTION OF THE ORGANIZATION}

The interaction between the professionals involved in a temporary organization of an engineering project is fundamental to the performance of the project (Svalestuen et al. 2015). To analyze the interaction of work teams, different tools can be used, such as frequency analysis, $\mathrm{n} \times \mathrm{n}$ matrix, and social network analysis (SNA), among others (Yang $\&$ Tang, 2004). Recently, the SNA has gained attention in the AEC industry because it can be used to understand the role of non-formal structures coexisting with formal ones.

Social networks are a set of relationships between actors who occupy different roles. The SNA uses the theory of graphs to explain these relationships with mathematical indicators, such as the density, length and diameter of the network (Marin \& Wellman 2011). SNA can be used as a diagnostic tool for the flow of information in the AEC industry (Alarcón et al. 2013). Flores et al. (2014) proposed the use of SNA, together with inferential statistical analysis and discussion roundtables, to improve the integration and connectivity of information flows in a project team.

\section{METHODOLOGY}

The research methodology is a case study of nine airport projects developed by the Ministry of Public Works of Chile. Five of these projects were in the initial study phase and preliminary projects, and the other four were in the final design and detail stage. In each project, the level of implementation of Lean practices, key performance indicators and social network metrics were assessed to understand the interaction of organizations.

Lean practices in the design stages were defined based on an extensive literature review of the last 10 years, which was then analyzed in interviews with ten professionals and academics experts. Performance indicators in the design were created based on the results of the team of researchers and professionals of the Ministry of Public Works. These indicators (Table 1) are adjusted to the major sources of waste generated in the design stages (Freire \& Alarcón 2002). These KPIs were measured during 5 weeks of each of the projects. The measurement was carried out through the report of each of the members of the design team on the following variables: total hours dedicated to the project, hours of rework, latency by request for information, number of errors detected, complete and committed activities. 
Table 1: KPIs for the design stage

\begin{tabular}{|c|c|}
\hline Name & Description \\
\hline Rework & $\begin{array}{l}\text { Percentage of hours that the design team is working on a task that had already } \\
\text { been done (rework) in proportion to the total time spent working on the project } \\
\text { in that week }\end{array}$ \\
\hline $\begin{array}{l}\text { Waiting } \\
\text { times }\end{array}$ & $\begin{array}{l}\text { Average waiting time that exists between the request and delivery of } \\
\text { information between two or more project members. }\end{array}$ \\
\hline $\begin{array}{l}\text { Quality } \\
\text { defects }\end{array}$ & $\begin{array}{c}\text { Number of failures, errors or nonconformities detected in the design process } \\
\text { per week }\end{array}$ \\
\hline $\begin{array}{l}\text { Commitment } \\
\text { achievement }\end{array}$ & Percentage of plan completed within the week (PPC) \\
\hline \multicolumn{2}{|c|}{$\begin{array}{l}\text { The analysis of social networks (SNA) was carried out according to the methodology } \\
\text { proposed by Alarcón et al. (2013), and included the following dimensions: knowledge of } \\
\text { roles, complete interaction, work information, planning and problem solving, learning, } \\
\text { and trust. The following indicators were obtained from each of the dimensions: number } \\
\text { of people, number of connections, density, diameter and average length. To collect the } \\
\text { data for these networks, an online survey was used, and the data were processed with the } \\
\text { Gephi Software. It is a tool to generate interaction graphs between different nodes, in this } \\
\text { case people, and that through graph theory obtains different mathematical metrics that } \\
\text { explain the relationships between the members of a design team. }\end{array}$} \\
\hline
\end{tabular}

\section{RESULTS AND DISCUSSION}

\section{CONTEXT OF CHILEAN AIRPORT PROJECTS}

The airport projects in Chile are supervised in the design and construction stage by the Airports Department (AD) of the Ministry of Public Works, while the person in charge of the operation is the Directorate General of Civil Aeronautics (DGCA). The AD hires a consulting company to carry out the design of the project in its stages of preliminary design and final design. The preliminary design goes through three reviews of the $\mathrm{AD}$ and the DGCA, and 6 to 10 people participate (designers and reviewers) in this stage. Meanwhile, the final design is divided into basic engineering and detailed engineering, each of them having three instances of revision by the AD and the DGCA and 9 to 22 people participate (designers and reviewers) in this stage.

The $\mathrm{AD}$, as an organization, has a group of professionals, mostly engineers and architects, who have two main functions within the team. The first is to review the designs and reports delivered by the consultant in each of the projects, and the second function is that of fiscal inspector (FI), a professional that is in charge of leading the reviewers team of a preliminary or a final design and that has a team of professionals with different specialties, among which some are from the $\mathrm{AD}$, and some are part of the Ministry of Public Works. Therefore, the same AD professional in the same moment of time can be the FI of a project and part of the team of professionals that reviews other projects. For airport projects, the AD plays a customer role. 
The DGCA is the institution in Chile responsible for operating the airport facilities, and therefore, within the development of the design of the projects, fulfills a user role. This organization has a group of professionals in charge of reviewing the projects and creating observations in its three instances.

The consultant is usually a highly complex engineering company that has several specialists who apply for a public tender to develop the design of an airport project, either the runway, the terminal building or other operational facilities. The consultant must appoint a project manager who oversees his team of designers and specialists and who is also the counterpart of the FI throughout the development of the project.

\section{LEAN PRACTICES: IDENTIFICATION AND ASSESSMENT}

From literature review and expert interviews about Lean management practices in the design stage, 19 practices were defined, which were categorized into dimensions of stakeholder management, planning and monitoring, problem solving and decision making. To measure management practices, the researchers applied a semi-structured interview to the IF of each project with open questions about each of the management practices. Based on these interviews, the researchers evaluated the actual practice at the level of implementation on a Likert scale from 1 to 5 , with 1 being that the practice did not exist and 5 that the practice was fully implemented.

- P1: Specialist designers get involved in the early stages of the project.

- P2: The builders are involved in the early stages of the project.

- P3: The requirements of the stakeholders are exhaustive, where they are defined as requirements, restrictions, technical specifications and special requirements.

- P4: The participation of the client in the design stage involves systematic participation and support in the decision-making meetings and resolution of problems.

- P5: The design of the product and the construction process are carried out simultaneously.

- P6: Project planning considers delivery date, phases, milestones, task subdivision and control instance. All of the above are immersed in a scheme in which gaps, buffers and points, are clarified so they can perform pull/push actions within the program.

- P7: Planning considers information about internal and/or external projects of the organization generated through a benchmarking exercise.

- P8: The planning is done collaboratively among several actors.

- P9: Planning is done at different levels (global, phase, intermediate and weekly).

- P10: The restrictions in the design process are identified, registered collaboratively and released by a responsible person. Then, they are followed up. 
- P11: The coordination of project information with the different stakeholders is done through a single platform, which allows systematic updating and continuous communication between the stakeholders.

- P12: There is a protocol to solve problems collaboratively.

- P13: The last planner identifies the problem and carries out a causal analysis (for example, 5 whys?).

- P 14: The solution to the problem is implemented, monitored and documented to verify that the problem was solved.

- P 15: In the decision-making process, options are evaluated, planned, and tested, and results are validated and applied.

- P 16: The time to make decisions is the last responsible moment and with all the information that can be gathered for that moment.

- P 17: To make decisions, information on internal and/or external projects of the organization is used, which is generated through a benchmarking exercise.

- P18: The decision-making mechanism is a meeting with those involved, where a formal technique is used, for example, WRC, AHP, CBA or other.

- P19: After the decision and actions are taken, it is verified if satisfactory results were obtained. In addition, the lessons learned are identified and documented.

Figure 1 shows the results of the measurement of the 19 management practices on a scale from 1 to 5, representing the level of implementation of each practice with the median of the nine projects. In addition, the graph shows the median of the 5 projects in the preliminary project stage (PD) and the median of the 4 projects in the final design stage (FD).

The practices with the highest level of implementation have to do with the surveying of stakeholders' requirements in a comprehensive manner and with the participation of the client in a systematic and empowered manner. Both practices have an outstanding level of implementation due mainly to the fact that the AD functions as a technical entity for the revision of designs rather than only for administrative purposes. This technical profile helps them to be more empowered in the decisions that are made during the design.

In contrast, the practices with the lowest level of implementation are those that must have early involvement of the builders, and therefore the design of the construction process is not carried out simultaneously with the design of the product. In addition, the use of information from previous projects for planning, problem solving and decision making of current projects have a low level of implementation. This is generated due to a poor culture of knowledge management, in addition to not having the appropriate computer systems to take advantage of so much prior information. Finally, a last lowimplementation practice has to do with the collaborative work at the time of planning and with the standardization of the process of monitoring the projects. 
When comparing projects in PD and FD, projects in a preliminary stage (PD) stand out when including specialist designers from the beginning (P1), while projects in a final design stage (FD) stand out in the planning practices, both in their level of detail and in the tools used for monitoring (P6 and P9) and in decision making (P13 and P16).

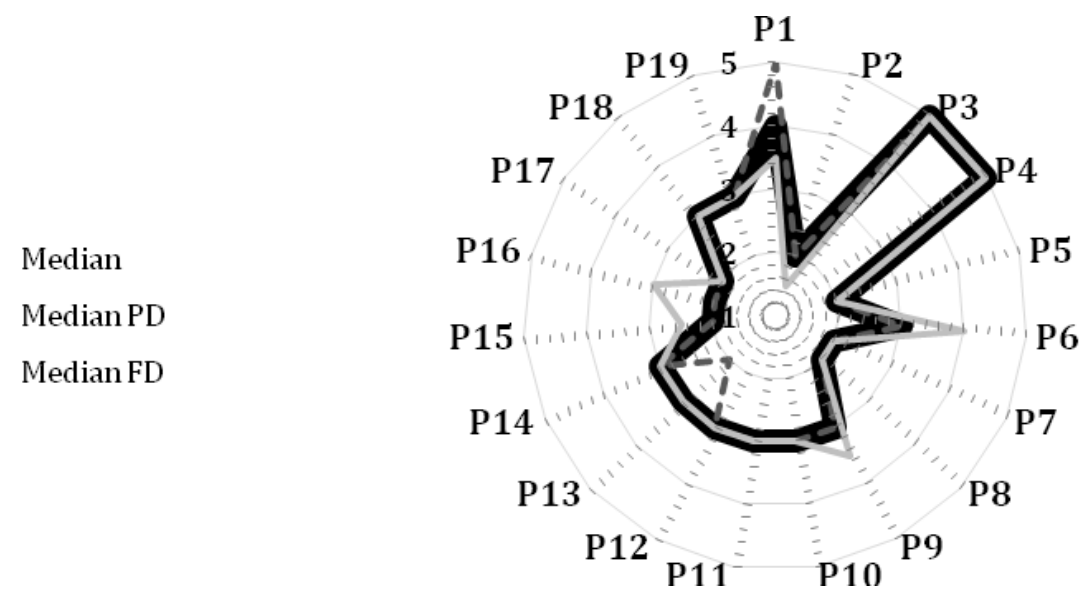

Figure 1: Lean practices assessment

\section{KPIS: IDENTIFICATION AND ASSESSMENT}

Table 2 shows the mean and the standard deviation (STD) of the 9 projects in general, of the projects in the preliminary design (PD) stage and the final design (FD) stage.

The average weekly rework of the nine projects oscillates within $20 \%$ of the hours dedicated; that is, one in five days is dedicated only to rework. It is important to mention that the airport projects of Chile define instances of revision and correction; therefore, there are weeks in which the projects have a high level of rework. This explains the high variability of the percentage of rework among the nine projects. In the PD stages, the average rework percentage is approximately 26\%, while in the FD stages, it reaches $14 \%$. This is mainly because during the PD stages, there is a high level of uncertainty in the design, which does not occur in the FD stage.

The average waiting time for information is 9.78 hours; that is slightly more than a day of work. Again, there is a significant difference between the projects in the PD stage and in the FD stage, with the longest duration in the first stage (12.55 average hours), while in the FD stage, the average time is 6.44 hours. This is mainly because FD times are shorter, which forces the consultant and the client to have a faster information flow. Even so, these latencies appear to be reasonably short compared to the typical latencies in the construction phase of international projects.

The average number of quality errors detected per week fluctuates between 0 and 6 . This is mainly due to the revision and correction times that exist in the planning of the project. In this case, the projects in the FD stage have a higher number of quality errors than the PD projects because in the FD stage, the number of designers and other 
interested parties increases significantly, causing an increase in the probability of finding errors and incompatibilities between the different specialties.

Finally, the fulfillment of the weekly commitments in each project, which averages approximately $75 \%$, without significant differences in the different stages of the projects. It is important to highlight that the percentage of activities that are not achieved is directly related to the percentage of unplanned rework that must be carried out week by week, which is approximately $20 \%$.

Table 2: KPIs assessment

\begin{tabular}{ccccccc}
\hline KPI & Mean & PD Mean & FD Mean & STD & PD STD & FD STD \\
\hline Rework (\%) & 20.94 & 26.08 & 14.51 & 17.40 & 17.12 & 15.50 \\
Waiting time (hours) & 9.78 & 12.45 & 6.44 & 6.69 & 7.00 & 4.42 \\
Quality defects (\#) & 2.87 & 2.04 & 3.90 & 2.33 & 2.03 & 2.27 \\
Commitment achievement & 74.85 & 75.85 & 73.60 & 13.71 & 8.26 & 0.00
\end{tabular}

\section{SNA: IDENTIFICATION AND ASSESSMENT}

Figure 2 shows the average density metric ( 0 to 1$)$ of the networks that were measured as well as a partial average calculated for the projects in the PD stage and in the FD stage. Segarra et al. (2017) present a direct relationship between the number of teams and the density of the work information flow, where a project with two teams (in this case designers and reviewers) should have a density close to $50 \%$, however, airport projects have an average density of close to $40 \%$, i. e. their density of work information is lower than other projects. One of the fundamental characteristics is that the network of knowledge of roles is practically the same as the network of complete interaction, both in the form of the network and in its metrics. This means that if people do not know what another person does in a project, they do not interact. After a workshop with the study participants, an emphasis was given to the kick-off meetings of each project.

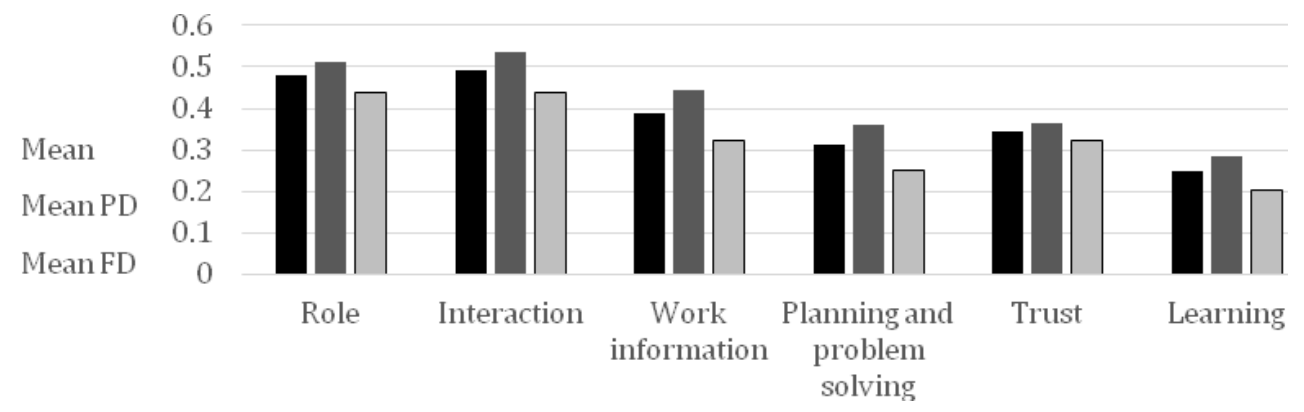

Figure 2. Social Network Density

Another important element to emphasize is that the learning network is born from the trust network; this means that there is no learning among people as long as there is no trust relationship that supports it. On the other hand, the network for planning and solving problems always focuses on positions with responsibility in the project team, which is 
directly related to a poor practice of collaborative planning. Finally, Figure 2 shows that PD projects have a higher density than in the FD stage, mainly due to the growth of the number of people in the team, as presented in the research by Segarra et al. (2017).

\section{CONCLUSIONS}

From the results, it is possible to draw the following conclusions: At the level of literature review and interviews with experts, Lean practices in design focus on stakeholder management, planning and monitoring, and problem solving and decision making. In the public projects that were evaluated, it was possible to identify that the practices with the greatest development are the management of requirements and the systematic participation of the clients, while the ones with the worst performance are the early involvement of builders and collaborative work. The projects in the preliminary stage stand out in the involvement of designers from the beginning and the projects in the final design stage in the planning and monitoring tools. These practices have a direct impact on the interaction between the different professionals in the organization, which is represented by a low level of work information flow and in the planning and resolution of problems. Considering that the members of the temporary organization do not necessarily know the role that other members of the team have, the kick-off meetings are essential to initiate the expected interaction between the different professionals. The low level of interaction directly affects the performance of the project, especially about rework (average 20\%) and design quality errors (average 3 per week), since this generates unplanned work that permeates the PPC of each project.

\section{ACKNOWLEDGMENTS}

We acknowledge AD and MOP for providing us with their information of airport projects. We acknowledge GEPUC. Herrera acknowledge financial support for PhD studies from VRI of PUC.

\section{REFERENCES}

AIA. (2007). Integrated Project Delivery: A Guide. USA. The American Institute of Architects.

Alarcón, D., Alarcón, I., and Alarcón, L. F. (2013). "Social Network Analysis a Diagnostic Tool for Information Flow in the AEC Industry." Proc. of the 21st Ann. Conf. of the Int'l Group for Lean Construction, Fortaleza, Brazil, 947-956.

Al Hattab, M., and Hamzeh, F. (2015). "Using social network theory and simulation to compare traditional versus BIM-lean practice for design error management." Automation in Construction, 52(4), 59-69. DOI: https://doi.org/10.1016/j.autcon.2015.02.014

Aziz, R. F., and Hafez, S. M. (2013). Applying lean thinking in construction and performance improvement. Alexandria Engineering Journal, 52(4), 679-695. DOI: https://doi.org/10.1016/j.aej.2013.04.008 
Baiden, B. K., Price, A. D. F., and Dainty, A. R. J. (2006). The extent of team integration within construction projects. International Journal of Project Management, 24, 13-23. DOI: https://doi.org/10.1016/j.ijproman.2005.05.001

Chan, A. P. C., and Chan, A. P. L. (2004). Key performance indicators for measuring construction success. Benchmarking: An International Journal, 11(2), 203-221. DOI: https://doi.org/10.1108/14635770410532624

Coates, P., Arayici, Y., Koskela, L., Kagioglou, M., Usher, C., and O'Reilly, K. (2010). "The key performance indicators of the BIM implementation process." Proc. International Conference on Computing in Civil and Building Engineering, Nothingham, UK.

Ebrahimy, Y., and Rokni, S. (2010). "Validity of industry benchmarks and metrics for engineering productivity." Proc. Construction Research Congress, Banff, Canada, 1057-1063.

Flores, J., Ruiz, J. C., Alarcón, D., Alarcón, L. F., Salvatierra, J. L., and Alarcón, I. (2014). "Improving Connectivity and Information Flow in Lean Organizations: Towards an Evidence-Based Methodology." Proc. of the 22nd Ann. Conf. of the Int'l Group for Lean Construction, Oslo, Norway, 1109-1120.

Fosse, R., and Ballard, G. (2016). "Lean design management in practice with the last planner system" Proc. of the 24th Ann. Conf. of the Int'l Group for Lean Construction, Boston, USA, 33-42.

Freire, J., and Alarcón, L. F. (2002). "Achieving Lean Design Process: Improvement Methodology." J. Constr. Eng. Manage., 128 (3), 248-256. DOI: https://doi.org/10.1061/(ASCE)0733-9364(2002)128:3(248)

Gambatese, J. A., Pestana, C., and Lee, H. W. (2017). "Alignment between Lean Principles and Practices and Worker Safety Behavior." J. Constr. Eng. Manage., 143(1). DOI: https://doi.org/10.1061/(ASCE)CO .1943-7862.0001209

Knotten, V., Svalestuen, F., and Hansen, G. (2016). "Improving design management with mutual assessment" Proc. of the 24th Ann. Conf. of the Int'l Group for Lean Construction, Boston, USA, 173-182.

Love, P. E., Irani, Z., Cheng, E., and Li, H. (2002). A model for supporting interorganizational relations in the supply chain. Engineering, Construction \& Architectural Management, 9(1), 2-15.

Marin, A., and Wellman, B. (2011). Social network analysis: An introduction. In J. Scott \& P. J. Carrington (Eds.), The SAGE handbook of social network analysis. London, pp. 11-25.

Segarra, L., Herrera, R. F., Alarcón, L. F., and Pellicer, E. (2017). "Knowledge Management and Information Flow Through Social Networks Analysis in Chilean Architecture Firms." Proc. of the 25th Ann. Conf. of the Int'l Group for Lean Construction, Walsh, K., Sacks, R., Brikalis, I. (eds.), Heraklion, Greece, 413-420.

Svalestuen, F., Frøystad, K., Drevland, F., Ahmad, S., Lohne, J., and Lædre, O. (2015). "Key Elements to an Effective Building Design Team." Proc. Computer Science, Nevada, USA, 838-843. 
Thomas, S., and Tang, Z. (2010). Labour-intensive construction sub-contractors: Their critical success factors. International Journal of Project Management, 28(7), 732-740. DOI: https://doi.org/10.1016/j.ijproman.2009.11.005

Yang, H., and Tang, J. (2004). "Team structure and team performance in IS development : a social network perspective." Information \& Management, 41, 335-349. DOI: https://doi.org/10.1016/S0378-7206(03)00078-8 